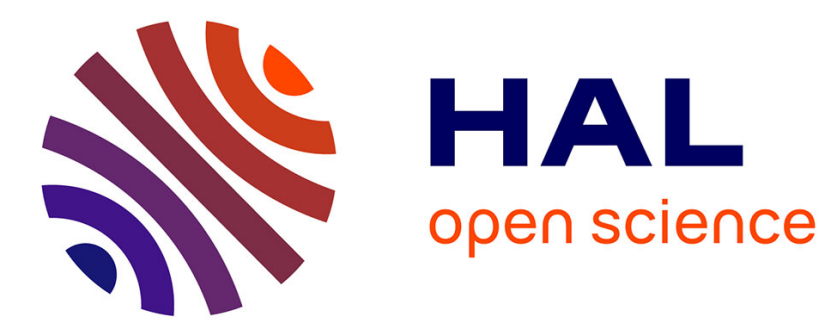

\title{
Nanocrystalline Zn2TiO4 films for distributed Bragg's reflectors operating in near infrared region
}

\author{
J. Mrázek, L. Spanhel, V. Matějec, I. Bartoň, R. Džunda, V. Puchý
}

\section{To cite this version:}

J. Mrázek, L. Spanhel, V. Matějec, I. Bartoň, R. Džunda, et al.. Nanocrystalline Zn2TiO4 films for distributed Bragg's reflectors operating in near infrared region. Optical Materials, 2021, 112, pp.110805. 10.1016/j.optmat.2021.110805 . hal-03130440

\author{
HAL Id: hal-03130440 \\ https://hal.science/hal-03130440
}

Submitted on 22 Feb 2021

HAL is a multi-disciplinary open access archive for the deposit and dissemination of scientific research documents, whether they are published or not. The documents may come from teaching and research institutions in France or abroad, or from public or private research centers.
L'archive ouverte pluridisciplinaire HAL, est destinée au dépôt et à la diffusion de documents scientifiques de niveau recherche, publiés ou non, émanant des établissements d'enseignement et de recherche français ou étrangers, des laboratoires publics ou privés. 
Nanocrystalline $\mathrm{Zn}_{2} \mathrm{TiO}_{4}$ films for distributed Bragg's reflectors operating in near infrared region

Jan Mrázek ${ }^{1}$, Lubomír Spanhel ${ }^{2}$, Vlastimil Matějec ${ }^{1}$, Ivo Bartoň ${ }^{1}$, Robert Džunda ${ }^{3}$, Viktor Puchý ${ }^{3}$

1 Institute of Photonics and Electronics of the Czech Academy of Sciences, Chaberská 57, 18251 Prague 8, Czech Republic

2 Sciences Chimiques de Rennes, UMR-CNRS 6226, Université de Rennes 1, Campus de Beaulieu, CS74205, F-35042 Rennes Cedex, France

3 The Institute of Materials Research of SAS, Watsonova 47, 04353 Kosice, Slovakia

Corresponding author:

Jan Mrázek

Institute of Photonics and Electronics AS CR, v.v.i

Chaberská 57

18251 Prague 8

Czech Republic

Tel: +420 266773558

Fax: +420284680222

E-mail: $\underline{\text { mrazek@ufe.cz }}$

\section{Keywords}

sol-gel, thin films, photonic crystals, nanocrystals, optical properties 


\begin{abstract}
We present a generic sol-gel approach for the preparation of a distributed Bragg reflector (DBR) based on combining nanocrystalline $\mathrm{Zn}_{2} \mathrm{TiO}_{4}$ with amorphous $\mathrm{SiO}_{2}$ xerogel films. We determined the effects of the annealing temperatures on the structural and optical properties of nanocrystalline $\mathrm{Zn}_{2} \mathrm{TiO}_{4}$ films. The increasing size of nanocrystals and film's density caused a regular growth of the films' refractive indices at $632 \mathrm{~nm}$ from the value of 1.837 to 1.960 . The acquired data were applied to design the DBR with tailored reflectance at $980 \mathrm{~nm}$ and the data predicted by the theoretical model were compared with experimental transmission and reflection spectra. Although the high optical losses caused by the Rayleigh scattering were observed at short wavelengths, the prepared films were fully transparent above $600 \mathrm{~nm}$. The uniform dielectric structure reflecting over $97 \%$ of incident light at 980 $\mathrm{nm}$ was prepared from eight Bragg's pairs. The normalized spectral bandwidth was about 0.22 . We proved the nanocrystalline films exhibiting scattering in UV-VIS spectral region can be used for the construction of the distributed Bragg's reflectors operating in near infrared region. The presented approach can be easily extended to other nanocrystalline films allowing the integration of nanocrystalline luminophores into advanced photonic structures.
\end{abstract}




\section{Introduction}

High-power photonics represents a progressive research field with a high application potential of results of the fundamental research in industry. Let us mention just several examples of recent advances, such as fiber lasers whose output powers have increased by several orders of magnitude to several hundred kilowatts over the last two decades [1] and the size of laser cavities has been miniaturized to the micro- and nano-scale [2], novel thermally-stable phosphors operating in "eye-safe" spectral range [3], etc. However, the high-power photonics have brought novel challenging requirements on the applied materials, the technology and the design of the photonic devices. With the growth of knowledge, simple photonic structures, such as antireflective coatings formed by a single layer, have been replaced by more sophisticated designs which allow to precisely tailor the properties of final photonic devices. Special interest has been paid to photonic crystals composed of the periodically arranged dielectric materials with dimensions comparable with the wavelength of the propagated electromagnetic (EM) wave, usually light [4]. The interaction of the EM wave with the photonic crystal limits their propagation due to a photonic band gap in such a crystal $[4,5]$. One-dimensional photonic crystals exhibiting a periodic modulation of the refractive index, $n$, in one direction are usually known as distributed Bragg's reflectors (DBR), or Bragg's mirrors [4,6]. Generally, they consist of a stack of alternating layers with low and high refractive indices. They are widely exploited to prepare coatings with tailored spectral reflectivity for dielectric mirrors [7], to improve the efficiency of solar cells [8], for the construction of laser cavities [4,6], optical waveguides [9], etc.

The application of DBRs in high-power photonic devices places special demands on the thermal stability of the applied materials. For the construction of DBR and optical microcavities, $\mathrm{SiO}_{2}$ with a tailored porosity is usually exploited as a low-refractive index layer [5]. Amorphous inorganic oxides represented by $\mathrm{TiO}_{2}, \mathrm{ZrO}_{2}, \mathrm{HfO}_{2}$ are widely used in high refractive index layers for their high refractive

index and high thermal stability $[5,6]$. However, these oxides suffer from several disadvantages that limit their application in high-power photonics. Low solubility of rare earth elements (RE) in the oxides $[10,11]$ does not allow to improve the output power of the active components and the local overheating can result to the recrystallization of the amorphous layers [12] resulting in the destruction of the DBR. These disadvantages can be suppressed when using materials based on the phase system $\mathrm{ZnO}-\mathrm{TiO}_{2}$ that provides several alternative compounds $[13,14]$ to the single oxides. Thus, cubic zinc titanates $\mathrm{Zn}_{2} \mathrm{TiO}_{4}$ and $\mathrm{ZnTiO}_{3}$ can be highly doped by $\mathrm{RE}[15,16]$ and the co-doping with $\mathrm{Yb}^{3+}$ ions supports the nonradiative transfers that can facilitate the pumping of active components through the absorption band of 
$\mathrm{Yb}^{3+}$ ions at $980 \mathrm{~nm}$ [17]. Corresponding nanocrystalline films with tailored structural and luminescence properties can be simply prepared by the sol-gel method [18] allowing a facile up-scaling of the preparation process [5]. However, the Rayleigh scattering on nanocrystals and the associated optical losses can be considered as a significant drawback limiting the application of nanocrystalline zinc titanates in DBR.

In this paper we show the nanocrystalline $\mathrm{Zn}_{2} \mathrm{TiO}_{4}$ films exhibiting scattering in UV-VIS spectral region can be used for the construction of DBR for near infrared region. We present a generic sol-gel approach for DBR fabrication based on combining nanocrystalline $\mathrm{Zn}_{2} \mathrm{TiO}_{4}$ with amorphous $\mathrm{SiO}_{2}$ xerogel films. We show the effects of processing parameters on the structural and optical properties of nanocrystalline $\mathrm{Zn}_{2} \mathrm{TiO}_{4}$ enabling to prepare the films with tailored properties and employ them for the fabrication of a DBR reflector operating at $980 \mathrm{~nm}$. We study the optical parameters of the prepared DBR and the experimental results compare with the data predicted by a numerical simulation. 


\section{Experimental}

\section{Simulation of DBR's optical properties}

We used a commercial software SpectraRay-3 (Sentech instruments $\mathrm{GmbH}$ ) to simulate the optical properties of prepared DBRs. A periodic structure of alternating low- and high- refractive index films was created on an infinite silica glass substrate covered by a single layer of nanocrystalline $\mathrm{Zn}_{2} \mathrm{TiO}_{4}$. The air was considered as a medium surrounding the designed DBR. Once the complex refractive indices and thicknesses were evaluated from experiments on single films they had been set as material constants for the particular model of DBR.

\section{Preparation of thin films and DBR}

All materials were prepared by the sol-gel method combined with the spin-coating deposition of thin films followed by rapid thermal treatment in a radiation furnace. The colloidal precursor of $\mathrm{Zn}_{2} \mathrm{TiO}_{4}$ was prepared by controlled hydrolysis of zinc(II)acetate dihydrate [16]. In the preparation, $6.56 \mathrm{~g}$ of titanium(IV)butoxide (Fluka, Purum) was dissolved under regular stirring in $250 \mathrm{ml}$ of absolute ethanol (Sigma-Aldrich, Spectranal grade), after which a total of $8.46 \mathrm{~g}$ of zinc(II)acetate dihydrate (Fluka, ACS reagent) was dispersed in the solution and stirred under ambient temperature till forming the transparent solution. The solution was refluxed at $86{ }^{\circ} \mathrm{C}$ for 32 hours and then allowed to cool. The solution was purified by filtration through a $0.2 \mu \mathrm{m}$ PTFE membrane and concentrated on a rotary evaporator to a final concentration of $\mathrm{Zn}_{2} \mathrm{TiO}_{4}$ equal to $0.3 \mathrm{~mol} \cdot \mathrm{I}^{-1}$.

The colloidal precursor of porous $\mathrm{SiO}_{2}$ was prepared by controlled hydrolysis of tetraethylorthosilicate (TEOS) (Sigma-Aldrich, $>98 \%$ ) by modification of the already published approach [19]. A solution prepared by mixing $3.5 \mathrm{ml}$ of demi-water, $100 \mu \mathrm{l}$ of $37 \%$ hydrochloric acid (SigmaAldrich, ACS reagent ), and $11 \mathrm{ml}$ of absolute ethanol (Sigma-Aldrich, Spectranal grade) was dropped to the solution prepared by dissolving $15 \mathrm{ml}$ of TEOS in $20 \mathrm{ml}$ of ethanol (Sigma-Aldrich, Spectranal grade). The resulting solution was refluxed at $86^{\circ} \mathrm{C}$ for $2 \mathrm{~h}$ and then allowed to cool. The final concentration of silicon in the sol was $2 \mathrm{~mol} \cdot \mathrm{I}^{-1}$. Referred approach allows to prepare mesoporous thin films exhibiting high durability and stability toward various vapors and industrial solvents. The presence of the pores caused the films' refractive index is lower than that of fully densified $\mathrm{SiO}_{2}[19]$. 
To prepare $\mathrm{Zn}_{2} \mathrm{TiO}_{4}$ single films, the colloidal precursor of $\mathrm{Zn}_{2} \mathrm{TiO}_{4}$ was spin-coated on a silica glass slide. The deposition was performed on a spin-coater WS-650-23B (Laurell) at a rotation speed of 2000 RPM. Applied gel layers were thermally treated in a rapid thermal annealing furnace (RTA) AccuThermo AW410 (Allwin21 corporation) for $60 \mathrm{~s}$ under an oxygen flow of $5 \mathrm{I} \cdot \mathrm{min}^{-1}$ and a heating rate of $10^{\circ} \mathrm{C} \cdot \mathrm{s}^{-1}$. The processing temperatures ranged from 500 to $1000^{\circ} \mathrm{C}$.

To prepare DBRs, the precursors were spin-coated on a silica glass slide (Schott) forming thin films of thicknesses $129 \mathrm{~nm}$ and $174 \mathrm{~nm}$ for $\mathrm{Zn}_{2} \mathrm{TiO}_{4}$ and porous $\mathrm{SiO}_{2}$, respectively. Each film was thermally treated in the RTA at $1000^{\circ} \mathrm{C}$ for $60 \mathrm{~s}$ under an oxygen flow of $5 \mathrm{I} \cdot \mathrm{min}^{-1}$ and a heating rate of $10{ }^{\circ} \mathrm{C} \cdot \mathrm{s}^{-1}$. The alternating deposition of the films followed by the thermal treatment was repeated until a designed number of Bragg's pairs was achieved.

\section{Structural and optical characterization}

X-ray diffraction (XRD) analyses were performed on a Bruker D8 Discover diffractometer with a Bragg-Brentano geometry operating with Cu-K $\alpha$ radiation $(\lambda=1.54056 \AA$, operating voltage $40 \mathrm{kV}$, current $40 \mathrm{~mA}$, integration time $200 \mathrm{~ms}$ ). The crystallized phase was compared to JCPDS data file number 18-1487 of $\mathrm{Zn}_{2} \mathrm{TiO}_{4}$. The mean nanocrystal size was calculated using in-build operating software. The film's crystallinity, $C_{r}$, expressed in per cents was calculated from Eq. (1).

$$
C_{r}=\frac{A_{t}}{A_{1000}} \cdot 100
$$

where $A_{t}$ is the integrated area of XRD peaks of the films thermally treated at temperature $t$ and $A_{1000}$ is the total integrated surface area of XRD peaks of the films thermally treated at $1000^{\circ} \mathrm{C}$.

The thicknesses and the structure of the films were analyzed by field emission scanning electron microscope (SEM). SEM images were taken with a JEOL JSM 7000F device (operating voltage $10 \mathrm{kV}$ ). To prevent sample charging a thin carbon layer was sputtered on the samples prior to the analyses.

UV-VIS and NIR transmission spectra were recorded in a transmittance and specular reflectance mode with a Lambda EZ 210 (Perkin-Elmer) and NIRQuest256-2.1 (Ocean Optics) spectrometers, respectively. The certified mirror STAN-SSH-NIST (Ocean Insight) was used as a reference sample to 
measure the spectral reflectance. Normal incidence was used at transmission spectra measurements and normal or inclined incidence of five degrees at recording reflection spectra.

Complex refractive indices of single films were determined by spectral ellipsometry. Spectroscopic ellipsometry data were recorded on the ellipsometer Sentech 850SE. The amplitude change $\tan (\psi)$ and the phase change $\cos (\Delta)$ were acquired in reflection mode over the spectral range of 300-1900 nm in air at room temperature. The refractive indices and absorption coefficients were calculated by the built-in Spectra Ray software. The applied ellipsometric model employed a single Cauchy's layer on a silica glass substrate (Palik) of infinite thickness. Spectral dependences of the refractive index, $n$, and the coefficient of optical losses, $k$, were expressed by Cauchy equations [20]:

$$
\begin{aligned}
& n=n_{0}+\frac{n_{1}}{\lambda^{2}}+\frac{n_{2}}{\lambda^{4}} \\
& k=k_{0}+\frac{k_{1}}{\lambda^{2}}+\frac{k_{2}}{\lambda^{4}}
\end{aligned}
$$

where $\lambda$ is the wavelength and $n_{0}, n_{1}, n_{2}, k_{0}, k_{1}, k_{2}$ are the fitted parameters. The parameters of the Cauchy's equations were optimized to minimize the mean square error (MSE) between the experimental results of $\tan (\psi)$ and $\cos (\Delta)$ and the corresponding simulated values. The film thickness was taken from SEM analysis.

The film's volume porosity $V_{p}$ was estimated from the bulk refractive index $n_{\text {bulk }}$ of $\mathrm{Zn}_{2} \mathrm{TiO}_{4}$ applying the Lorenz-Lorenz relationship [21]:

$$
V_{P}=1-\frac{\left(n^{2}-1\right) \cdot\left(n_{b u l k}^{2}+2\right)}{\left(n^{2}+2\right) \cdot\left(n_{b u l k}^{2}-1\right)}
$$

Assuming zero optical losses of single films in DBR, a minimum transmittance $T$ and the reflectivity $R$ of distributed Bragg reflectors can be expressed by Eq. (5) [22]:

$$
T=100 \times[1-R]=100 \times\left[1-\left(\frac{n_{\text {air }} \cdot n_{Z_{2} \mathrm{TiO}_{4}}^{2 \cdot N}-n_{\text {substrate }} \cdot n_{\text {SiO } 2}^{2 \cdot N}}{n_{\text {air }} \cdot n_{Z_{2} n_{2} \mathrm{TiO}_{4}}^{2 \cdot N}+n_{\text {substrate }} \cdot n_{\text {SiO } 2}^{2 \cdot N}}\right)^{2}\right]
$$

where $n_{\text {air, }} n_{\text {Zn2TiO4, }} n_{\text {SiO2 }}, n_{\text {substrate }}$ are the refractive indices of the air, the $\mathrm{Zn}_{2} \mathrm{TiO}_{4}$ and porous $\mathrm{SiO}_{2}$ alternating films forming the Bragg's pair, and the first $\mathrm{Zn}_{2} \mathrm{TiO}_{4}$ film on the silica substrate, respectively. $N$ is the total number of Bragg's pairs. 


\section{Results and discussion}

\section{Tailoring of structural and optical properties of $\mathrm{Zn}_{2} \mathrm{TiO}_{4}$ films}

Effects of processing parameters on the final nanoparticle size and film's structural properties must be exactly known to prepare films with precisely tailored optical properties. We focused on the effects $\mathrm{Zn}_{2} \mathrm{TiO}_{4}$ films' processing temperature as the most important processing parameter for nanocrystalization. To evaluate the formation and growth of $\mathrm{Zn}_{2} \mathrm{TiO}_{4}$ nanocrystals during the thermal treatment, XRD analyses were performed. Their results are demonstrated in Fig. 1 . The first diffraction pattern appeared in the film thermally treated at $600^{\circ} \mathrm{C}$ and it corresponded to pure $\mathrm{Zn}_{2} \mathrm{TiO}_{4}$. With raising the processing temperature, the diffraction peaks of $\mathrm{Zn}_{2} \mathrm{TiO}_{4}$ became more intensive and better pronounced. No traces of side-formed compounds such as $\mathrm{ZnO}$ or $\mathrm{TiO}_{2}$ were observed in the diffractograms. The temperature dependence of the mean nanocrystal size and the film's crystallinity, shown in Fig. 2, provided detailed information on nanocrystal growth. The mean nanocrystal size below $700{ }^{\circ} \mathrm{C}$ was nearly constant at around $14 \mathrm{~nm}$. Above $800^{\circ} \mathrm{C}$, the mean nanocrystal size regularly grew with increasing processing temperature reaching a final value of $52 \mathrm{~nm}$ for $1000^{\circ} \mathrm{C}$. The film's crystallinity rapidly grew from $77 \%$ for $600^{\circ} \mathrm{C}$ to $98.8 \%$ for $800^{\circ} \mathrm{C}$. The films thermally treated over $800^{\circ} \mathrm{C}$ exhibited crystallinity of almost $100 \%$ and an eventual deviation was within the measurement uncertainty of $0.05 \%$.

In our previous paper [16] we reported that the crystallization of $\mathrm{Zn}_{2} \mathrm{TiO}_{4}$ nanopowder occurs by homogenous nucleation controlled by the three-dimensional growth followed by cellular recrystallization. The films' crystallization exhibited very similar behavior. The curve shapes representing the mean nanocrystal size and the crystallinity in Fig. 2 indicated that the nucleation was a dominant crystallization process within a temperature range of $600-700^{\circ} \mathrm{C}$. Novel nanocrystals were formed in the amorphous films causing the rapid increase of the crystallinity over $90 \%$ but the nanocrystal's size was kept almost constant during the nucleation stage. The nucleation terminated below $800{ }^{\circ} \mathrm{C}$ and the recrystallization became a dominant process for higher temperatures causing the crystallinity reached the limiting value of $100 \%$ and the mean nanocrystal size regularly grew up over limits.

To evaluate principal optical properties of the single $\mathrm{Zn}_{2} \mathrm{TiO}_{4}$ films the spectroscopic ellipsometry analyses were performed. The fitted parameters of Cauchy's equations together with the film's thicknesses evaluated by SEM are summarized in Table 1. The shapes of the refractive indices' curves, Fig. 3a, were almost independent on the processing temperatures and showed normal material 
dispersion. The values of the refractive indices rapidly fall down with increasing wavelength in the spectral range from $300 \mathrm{~nm}$ to $900 \mathrm{~nm}$ and only moderate decrease was observed for wavelengths longer than $900 \mathrm{~nm}$ approaching the horizontal asymptote equal to the fitted parameter $n_{0}$.

As one can see from Table 1, an increase of the processing temperatures caused a regular growth of the films' refractive indices at $632 \mathrm{~nm}$ from a value of 1.837 to 1.960 and a monotonous decrease of the films' thicknesses from a value of $950 \mathrm{~nm}$ to $640 \mathrm{~nm}$ due to the films' densification. Spectral dependences of the extinction coefficient in Fig. 3b, followed the trends observed for the refractive indices except for the sample thermally treated at $500{ }^{\circ} \mathrm{C}$ which was fully transparent. Values of the extinction coefficient recorded at $632 \mathrm{~nm}$ grew accumulatively from $1.04 \cdot 10^{-6}$ to $2.34 \cdot 10^{-6}$ for the annealing temperatures ranging from $600^{\circ} \mathrm{C}$ to $1000{ }^{\circ} \mathrm{C}$, respectively.

Film's optical properties reflected the nanocrystal's growth and the films' densification occurring during the thermal treatment. The formation of nanocrystals exhibiting a higher refractive index than the original amorphous film together with the films' densification significantly contributed to the regular increase of the refractive indices. Although the films were completely crystallized, the refractive index's final value did not reach the value of 2.1 reported for single-crystalline $\mathrm{Zn}_{2} \mathrm{TiO}_{4}$ [23]. Such a disproportion can be attributed to the presence of pores remaining in the films. It is generally accepted that the films prepared by the sol-gel method exhibit residual porosity formed by the evaporation of solvents and decomposition of the chemical by-products entrapped in the gel matrix during the thermal treatment. Considering the pores were homogenously distributed in the film nanocrystalline matrix and filled by the air, a final film volume porosity, calculated from the Lorenz-Lorenz approximation represented by the Eq. (4), was of $11.9 \%$. More densified films exhibiting a higher refractive index can be prepared by increasing the processing temperature or by prolongation of the annealing time. However, in such conditions, the increasing nanocrystal size will significantly contribute to the Rayleigh scattering that is reciprocal to the fourth power of the wavelength [24] and corresponds to the term $k_{2}$ of the coefficient of optical losses calculated by Cauchy's approximation in Eq. (3). According to the presented results, the films processing temperature should be optimized to achieve the highest possible refractive index of the film while avoiding overlapping a range of high optical losses with the Bragg's peak position. For the construction of optical components operating in near infrared, where the contribution of the Rayleigh scattering to the overall optical losses is negligible or completely zero, even films exhibiting scattering in UV-VIS spectral region can be used. 


\section{Fabrication and properties of DBR}

To prepare the DBR operating at $980 \mathrm{~nm}$ and to meet all the introduced criteria on the film optical properties, the films were thermally treated at $1000^{\circ} \mathrm{C}$. For this processing temperature the refractive index of the $\mathrm{Zn}_{2} \mathrm{TiO}_{4}$ film was 1.910. The refractive index of the $\mathrm{SiO}_{2}$ film was equal to 1.421 and the reported value [19] was verified by spectroscopic ellipsometry analysis provided in the Supplementary Interactive Plot Data. To achieve the Bragg's reflection centered at $980 \mathrm{~nm}, \lambda_{980}$, the Bragg's condition [5]:

$$
\lambda_{980}=4 \cdot n_{\mathrm{Zn}_{2} \mathrm{TiO}_{4}} \cdot t_{\mathrm{Zn}_{2} \mathrm{TiO}_{4}}=4 \cdot n_{\mathrm{SiO}_{2}} \cdot t_{\mathrm{SiO}_{2}},
$$

where $t$ represents the thicknesses of denoted films, was met for the thicknesses of $\mathrm{Zn}_{2} \mathrm{TiO}_{4}$ and $\mathrm{SiO}_{2}$ films equal to $129 \mathrm{~nm}$ and $172 \mathrm{~nm}$, respectively. Deviation in the film thicknesses led to phase mismatch at the $\mathrm{Zn}_{2} \mathrm{TiO}_{4}-\mathrm{SiO}_{2}$ interfaces and reduced the Bragg's reflection theoretical values. The scheme of the designed DBR structure is demonstrated in the Fig. 4.

In Fig. 5 we show secondary electron SEM images of a prepared DBR. The alternating bright and dark strips represented $\mathrm{Zn}_{2} \mathrm{TiO}_{4}$ and low-atomic number $\mathrm{SiO}_{2}$ layers, respectively. The layers were smooth and highly uniform on a macroscale. The $\mathrm{Zn}_{2} \mathrm{TiO}_{4}$ layers consisted of closely packed nanocrystals of the mean size of $50 \pm 5 \mathrm{~nm}$. This observation well matched the nanocrystal size of $52 \mathrm{~nm}$ calculated from XRD records for the single layer of $\mathrm{Zn}_{2} \mathrm{TiO}_{4}$. The grown nanocrystals partially interfered into the amorphous layers of $\mathrm{SiO}_{2}$ causing the irregularities at the $\mathrm{Zn}_{2} \mathrm{TiO}_{4}-\mathrm{SiO}_{2}$ interfaces at a level of about 5 $\mathrm{nm}$. Although the refractive index of $\mathrm{SiO}_{2}$ layers was smaller than that of 1.457 reported for fused silica glass [20] the presence of pores was not observed by SEM. This observation supports the theory the $\mathrm{SiO}_{2}$ layers were formed by mesoporous xerogel with a closed pore structure [19].

Although the reflectivity is a key property of DBRs, transmittance spectra provide the information on the effects of the nanostructure and DBR's design on the overall optical properties in more details. Fig. 6 shows the evolution of the DBR's transmittance spectra with the increasing number of Bragg's pairs and Fig. 7 summarizes the transmittance minimum of the Bragg's band at $980 \mathrm{~nm}$. From the general point of view, the experimental data were in good agreement with the predicted theoretical values. The interference fringes were asymmetrically distributed around the absorption band at $980 \mathrm{~nm}$ and arranged more densely at shorter wavelengths according to the refractive-index dispersion. The Rayleigh scattering on the nanocrystals caused the transmittance gradually decreased for wavelengths shorter than $600 \mathrm{~nm}$. The spectra appeared two major Bragg's bands centered around $350 \mathrm{~nm}$ and 980 
$\mathrm{nm}$. The imperfections at the layers' interfaces caused the Bragg's bands minima oscillated slightly around their central positions with the increasing number of layers applied. With the increasing number of Bragg's pairs the Bragg's bands became better pronounced and the transmittance of the Bragg's band at $980 \mathrm{~nm}$ rapidly fall down reaching a minimum of $2.87 \%$. To further reduce the transmittance the additional Bragg's pairs must be applied. For the selected materials the DBR must consist of a total of twenty Bragg's pairs to achieve the transmittance lower than $0.01 \%$ as the equivalent to the optical filters having an optical density of 4 . Although the optical contrast given by the difference of the layers' refractive indices $\left(n_{\mathrm{Zn} 2 \mathrm{TiO} 4}-n_{\mathrm{SiO} 2}\right)$ was 0.49 only, the achieved parameters were fully comparable with the values reported for high refractive-index contrast materials [25]. In our work, five Bragg's pairs were necessary to achieve the transmittance lower than 0.16, while four Bragg's pairs had to be prepared to achieve this value using $\mathrm{TiO}_{2}$ and highly porous $\mathrm{SiO}_{2}$ layers $[7,25]$. A presence of an absorption band around $490 \mathrm{~nm}$ in Fig. 6, represents a noticeable disagreement between the experimental and the theoretical data. In all experiments this band's position was located exactly at one half of the wavelength of the peak at $980 \mathrm{~nm}$. Reasons for this result were not entirely understood but in our opinion it is related to the second harmonic frequency detected by the spectrophotometer.

Fig. 8 shows the spectral specular reflectance of the final DBR. The specular reflectance curves were complementary to the transmittance spectra and the maximal reflectance of the DBR band at $980 \mathrm{~nm}$ was higher than $97 \%$. Normalized spectral bandwidth (NSB), calculated as a ratio of FWHM over the Bragg's band central spectral position of, was about 0.22 . Although the smaller values are preferred to prepare very selective resonators and larger values around 0.4 are favorable for the construction of broad spectral reflectors for solar cells [8], the NSB of the DBR band in this paper was sufficient to fully cover the spectral region where the typical absorption band of $\mathrm{Yb}^{3+}$ ions is localized [18]. Therefore, the demonstrated DBR is suitable for the construction of resonators for Yb-pumped laser devices. From a general point of view, the Bragg's bands localized at shorter wavelengths can be used for the construction of DBR too, as can be seen on the Bragg's band at $350 \mathrm{~nm}$. The reflectivity in this area is higher due to the higher optical contrast of the layers and can be further improved by optimizing the layer thicknesses. However, the Rayleigh scattering on the nanocrystals significantly reduced the DBR reflectivity to two-thirds of the theoretical value in favor of the absorption. Such a limitation is not very important in case of applications where the reflected light intensity is not a key parameter, usually DBR's sensors monitoring the spectral shift of the Bragg's band [25], reference beam splitters [26], etc. But it acquires importance in case of high-power components where the high intensity of the scattering light 
can exceed an optical breakdown threshold resulting in the destruction of the photonic devices [27] or recrystallization of the amorphous layers [12].

\section{Conclusions}

We presented a generic sol-gel approach for the preparation of distributed Bragg reflector by combining nanocrystalline $\mathrm{Zn}_{2} \mathrm{TiO}_{4}$ with amorphous porous $\mathrm{SiO}_{2}$ xerogel films. We have experimentally determined the effects of the processing temperature on the structural and optical properties of nanocrystalline $\mathrm{Zn}_{2} \mathrm{TiO}_{4}$ films and evaluated the film optical constants. The acquired data were applied to design the distributed Bragg reflector with tailored reflectance at $980 \mathrm{~nm}$. Although the high optical losses caused by the Rayleigh scattering were observed at wavelengths shorter than $600 \mathrm{~nm}$, a uniform dielectric structure reflecting over $97 \%$ of incident light at $980 \mathrm{~nm}$ was prepared by alternating eight Bragg's pairs. Thus, we proved that the nanocrystalline films exhibiting scattering in UV-VIS spectral region can be used for the construction of distributed Bragg's reflectors for near infrared region. The presented approach can be easily extended to other nanocrystalline films accessible by sol-gel method allowing the integration of nanocrystalline luminophores with improved optical properties into advanced photonic structures and devices.

\section{Conflicts of interest}

There are no conflicts to declare.

\section{Acknowledgements}

The authors acknowledge the financial support from the Czech Science Foundation under contract $\mathrm{N}^{\circ} 16-10019 \mathrm{~S}$.

\section{References}

[1] I. Kasik, P. Peterka, J. Mrazek, P. Honzatko, Silica Optical Fibers Doped with Nanoparticles for Fiber Lasers and Broadband Sources, Curr. Nanosci. 12 (2016) 277-290.

https://doi.org/10.2174/1573413711666150624170638.

[2] M. Guina, A. Rantamaki, A. Harkonen, Optically pumped VECSELs: review of technology and progress, J. Phys. -Appl. Phys. 50 (2017). https://doi.org/10.1088/1361-6463/aa7bfd. 
[3] G.A. Kumar, M. Pokhrel, D.K. Sardar, P. Samuel, K.I. Ueda, T. Yanagitani, H. Yagi, 2.1 mu m Emission Spectral Properties of Tm and Ho Doped Transparent YAG Ceramic, Sci. Adv. Mater. 4 (2012) 617622. https://doi.org/10.1166/sam.2012.1328.

[4] P. Lova, G. Manfredi, D. Comoretto, Advances in Functional Solution Processed Planar 1D Photonic Crystals, Adv. Opt. Mater. 6 (2018). https://doi.org/10.1002/adom.201800730.

[5] B. Brudieu, A. Le Bris, J. Teisseire, F. Guillemot, G. Dantelle, S. Misra, P. Roca i Cabarrocas, F. Sorin, T. Gacoin, Sol-Gel Route Toward Efficient and Robust Distributed Bragg Reflectors for Light Management Applications, Adv. Opt. Mater. 2 (2014) 1105-1112. https://doi.org/10.1002/adom.201400292.

[6] R.M. Almeida, S. Portal, Photonic band gap structures by sol-gel processing, Curr. Opin. Solid State Mater. Sci. 7 (2003) 151-157. https://doi.org/10.1016/s1359-0286(03)00045-7.

[7] R.S. Dubey, V. Ganesan, Fabrication and characterization of TiO2/SiO2 based Bragg reflectors for light trapping applications, Results Phys. 7 (2017) 2271-2276. https://doi.org/10.1016/j.rinp.2017.06.041.

[8] M.E. Calvo, Materials chemistry approaches to the control of the optical features of perovskite solar cells, J. Mater. Chem. A. 5 (2017) 20561-20578. https://doi.org/10.1039/c7ta05666d.

[9] I. Barton, V. Matejec, J. Mrazek, L. Predoana, M. Zaharescu, Properties of silica and silica-titania layers fabricated from silica sols containing fumed silica, Opt. Mater. 77 (2018) 187-197. https://doi.org/10.1016/j.optmat.2018.01.037.

[10] S.R. Johannsen, L.R. Lauridsen, B. Julsgaard, P.T. Neuvonen, S.K. Ram, A.N. Larsen, Optimization of Er3+-doped TiO2-thin films for infrared light up-conversion, THIN SOLID FILMS. 550 (2014) 499503. https://doi.org/10.1016/j.tsf.2013.10.123.

[11] G. Ehrhart, M. Bouazaoui, B. Capoen, V. Ferreiro, R. Mahiou, O. Robbe, S. Turrell, Effects of rareearth concentration and heat-treatment on the structural and luminescence properties of europiumdoped zirconia sol-gel planar waveguides, Opt. Mater. 29 (2007) 1723-1730. https://doi.org/10.1016/j.optmat.2006.09.006.

[12] J. Mrazek, J. Aubrecht, F. Todorov, J. Bursik, V. Puchy, R. Dzunda, S. Vytykacova, I. Kasik, CO2 laser-assisted preparation of transparent Eu2Ti2O7 thin films, Ceram. Int. 44 (2018) 9479-9483. https://doi.org/10.1016/j.ceramint.2018.02.165. 
[13] J. Mrazek, L. Spanhel, G. Chadeyron, V. Matejec, Evolution and Eu3+ Doping of Sol-Gel Derived Ternary ZnxTiyOz - Nanocrystals, J. Phys. Chem. C. 114 (2010) 2843-2852. https://doi.org/10.1021/jp9036217.

[14] N.T. Nolan, M.K. Seery, S.C. Pillai, Crystallization and Phase-Transition Characteristics of Sol-GelSynthesized Zinc Titanates, Chem. Mater. 23 (2011) 1496-1504. https://doi.org/10.1021/cm1031688.

[15] T. Aubert, F. Grasset, M. Potel, V. Nazabal, T. Cardinal, S. Pechev, N. Saito, N. Ohashi, H. Haneda, Synthesis and characterization of Eu3+, Ti4+@ZnO organosols and nanocrystalline c-ZnTiO3 thin films aiming at high transparency and luminescence, Sci. Technol. Adv. Mater. 11 (2010). https://doi.org/10.1088/1468-6996/11/4/044401.

[16] J. Mrazek, L. Spanhel, M. Surynek, M. Potel, V. Matejec, Crystallization properties of RE-doped $(\mathrm{RE}=\mathrm{Eu}, \mathrm{Er}, \mathrm{Tm}) \mathrm{Zn}(2) \mathrm{TiO}(4)$ prepared by the sol-gel method, J. Alloys Compd. 509 (2011) 40184024. https://doi.org/10.1016/j.jallcom.2011.01.009.

[17] K. Kobwittaya, Y. Oishi, T. Torikai, M. Yada, T. Watari, H.N. Luitel, Bright red upconversion luminescence from Er3+ and $\mathrm{Yb3}+$ co-doped $\mathrm{ZnO}-\mathrm{TiO} 2$ composite phosphor powder, Ceram. Int. 43 (2017) 13505-13515. https://doi.org/10.1016/j.ceramint.2017.07.056.

[18] O.S. Dymshits, P.A. Loiko, N.A. Skoptsov, A.M. Malyarevich, K.V. Yumashev, A.A. Zhilin, I.P. Alekseeva, M.Ya. Tsenter, K. Bogdanov, Structure and upconversion luminescence of transparent glass-ceramics containing (Er,Yb)(2)(Ti,Zr)(2)O-7 nanocrystals, J. Non-Cryst. SOLIDS. 409 (2015) 5462. https://doi.org/10.1016/j.jnoncrysol.2014.11.012.

[19] M. Zaharescu, A. Barau, L. Predoana, M. Gartner, M. Anastasescu, J. Mrazek, I. Kasik, V. Matejec, TiO2-SiO2 sol-gel hybrid films and their sensitivity to gaseous toluene, J. Non-Cryst. Solids. 354 (2008) 693-699. https://doi.org/10.1016/j.jnoncrysol.2007.07.098.

[20] R.M.A. Azzam, N.M. Bashara, Ellipsometry and polarized light, North-Holland : Sole distributors for the USA and Canada, Elsevier Science Pub. Co., Amsterdam; New York, 1987.

[21] J. Mrazek, S. Vytykacova, J. Bursik, V. Puchy, V. Girman, P. Peterka, I. Kasik, Sol-gel route to nanocrystalline Eu2Ti2O7 films with tailored structural and optical properties, J. Am. Ceram. Soc. 102 (2019) 6713-6723. https://doi.org/10.1111/jace.16524. 
[22] C.J.R. Sheppard, Approximate calculation of the reflection coefficient from a stratified medium, Pure Appl. Opt. J. Eur. Opt. Soc. Part A. 4 (1995) 665.

[23] L. Li, Y. Fan, D.J. Wang, G.L. Feng, D.P. Xu, Refractive index dispersion of spinel Zn2TiO4 single crystal, Cryst. Res. Technol. 46 (2011) 475-479. https://doi.org/10.1002/crat.201100068.

[24] A. Usami, H. Ozaki, Optical modeling of nanocrystalline TiO2 films, J. Phys. Chem. B. 109 (2005) 2591-2596. https://doi.org/10.1021/jp040178y.

[25] M. Anaya, A. Rubino, M.E. Calvo, H. Miguez, Solution processed high refractive index contrast distributed Bragg reflectors, J. Mater. Chem. C. 4 (2016) 4532-4537. https://doi.org/10.1039/c6tc00663a.

[26] R.S. Dubey, V. Ganesan, Visible and near-infrared wavelength-selective dielectric reflectors for light management applications, Superlattices Microstruct. 122 (2018) 228-234. https://doi.org/10.1016/j.spmi.2018.08.005.

[27] A.V. Smith, B.T. Do, Bulk and surface laser damage of silica by picosecond and nanosecond pulses at 1064 nm, Appl. Opt. 47 (2008) 4812-4832. https://doi.org/10.1364/AO.47.004812. 
Table 1 Summary of thicknesses of $\mathrm{Zn}_{2} \mathrm{TiO}_{4}$ films and the fitted parameters of Cauchy's equations

\begin{tabular}{cccccccc}
\hline Component & $\begin{array}{c}\text { Temperature } \\
\left({ }^{\circ} \mathrm{C}\right)\end{array}$ & $\begin{array}{c}\text { Thickness } \\
(\mathrm{nm})\end{array}$ & $\mathrm{n}_{0}$ & $\begin{array}{c}\mathrm{n}_{1} \\
\left(10^{2} \mathrm{~nm}^{2}\right)\end{array}$ & $\begin{array}{c}\mathrm{n}_{2} \\
\left(10^{7} \mathrm{~nm}^{4}\right)\end{array}$ & $\begin{array}{c}\mathrm{k}_{2} \\
\left(10^{-6} \mathrm{~nm}^{4}\right)\end{array}$ & MSE \\
\hline $\mathrm{Zn}_{2} \mathrm{TiO}_{4}$ & 500 & $950 \pm 10$ & $1.785 \pm 0.002$ & $181 \pm 2$ & $114 \pm 1$ & $0 \pm 0.02$ & 0.037 \\
$\mathrm{Zn}_{2} \mathrm{TiO}_{4}$ & 600 & $860 \pm 10$ & $1.804 \pm 0.002$ & $205 \pm 2$ & $96 \pm 1$ & $1.67 \pm 0.02$ & 0.060 \\
$\mathrm{Zn}_{2} \mathrm{TiO}_{4}$ & 700 & $730 \pm 10$ & $1.829 \pm 0.002$ & $214 \pm 2$ & $62 \pm 1$ & $2.15 \pm 0.02$ & 0.045 \\
$\mathrm{Zn}_{2} \mathrm{TiO}_{4}$ & 800 & $705 \pm 10$ & $1.850 \pm 0.002$ & $204 \pm 2$ & $103 \pm 1$ & $2.53 \pm 0.02$ & 0.082 \\
$\mathrm{Zn}_{2} \mathrm{TiO}_{4}$ & 900 & $650 \pm 5$ & $1.868 \pm 0.002$ & $224 \pm 2$ & $110 \pm 1$ & $3.27 \pm 0.02$ & 0.062 \\
$\mathrm{Zn}_{2} \mathrm{TiO}_{4}$ & 1000 & $640 \pm 5$ & $1.88 \pm 0.002$ & $289 \pm 2$ & $111 \pm 1$ & $3.71 \pm 0.02$ & 0.074 \\
porous SiO $_{2}$ & 1000 & $430 \pm 5$ & $1.420 \pm 0.002$ & $14 \pm 2$ & $8.3 \pm 0.5$ & $0 \pm 0.02$ & 0.042
\end{tabular}




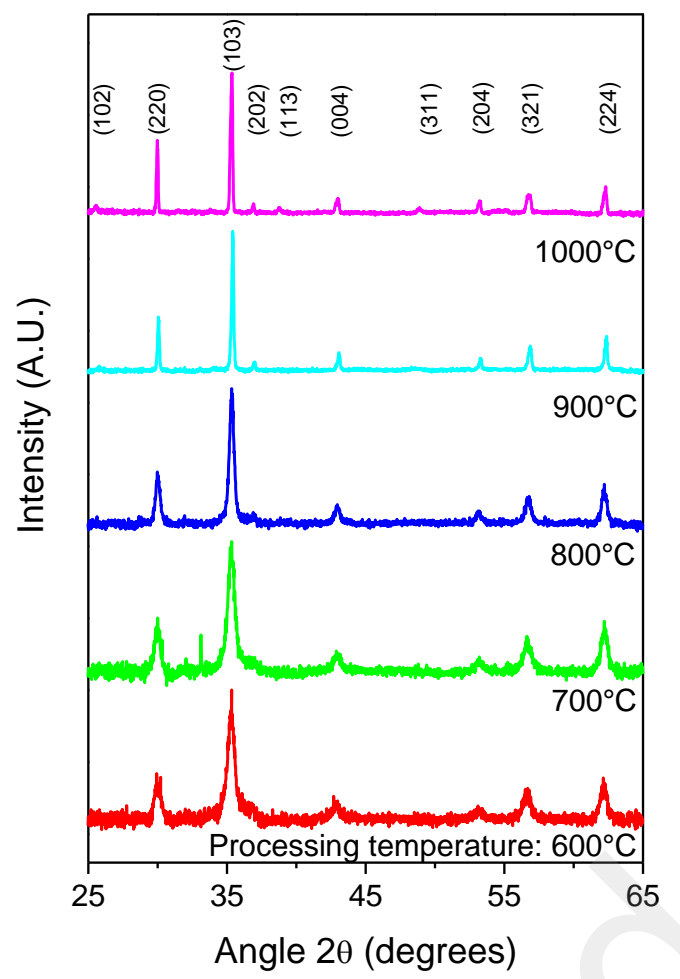

Figure 1. XRD records of thermally treated $\mathrm{Zn}_{2} \mathrm{TiO}_{4}$ layers with denoted (hkl) indices according to JCPDS data file number 18-1487. 


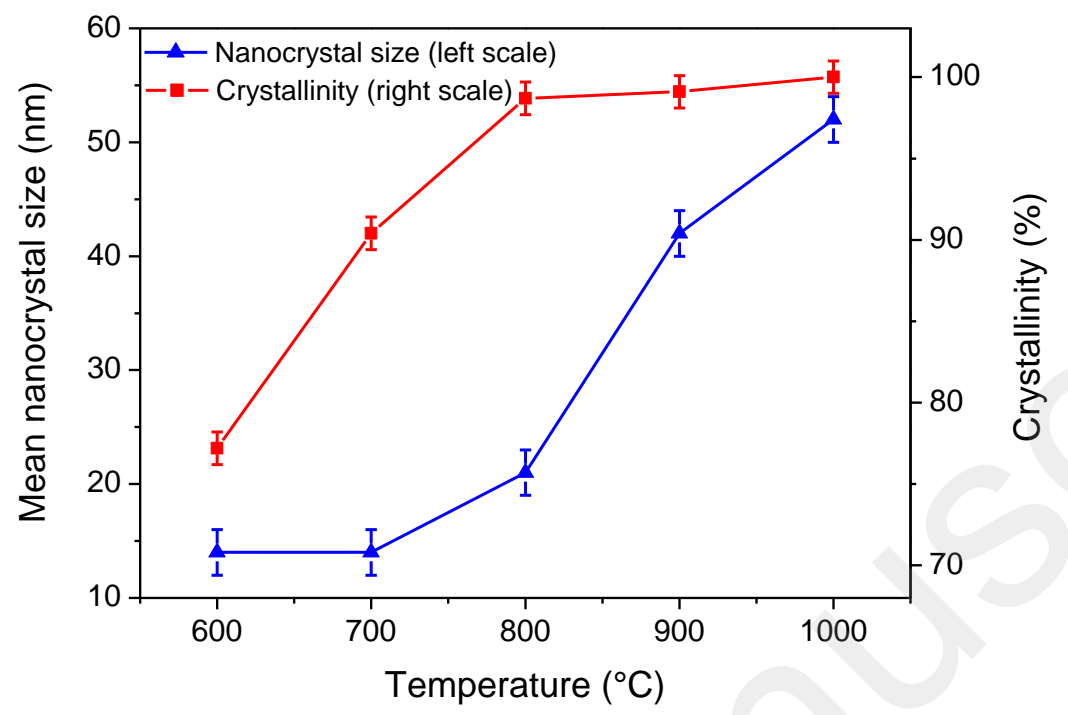

Figure 2. The temperature dependence of mean size of $\mathrm{Zn}_{2} \mathrm{TiO}_{4}$ nanocrystals (left axis) and the crystallinity (right axis). 

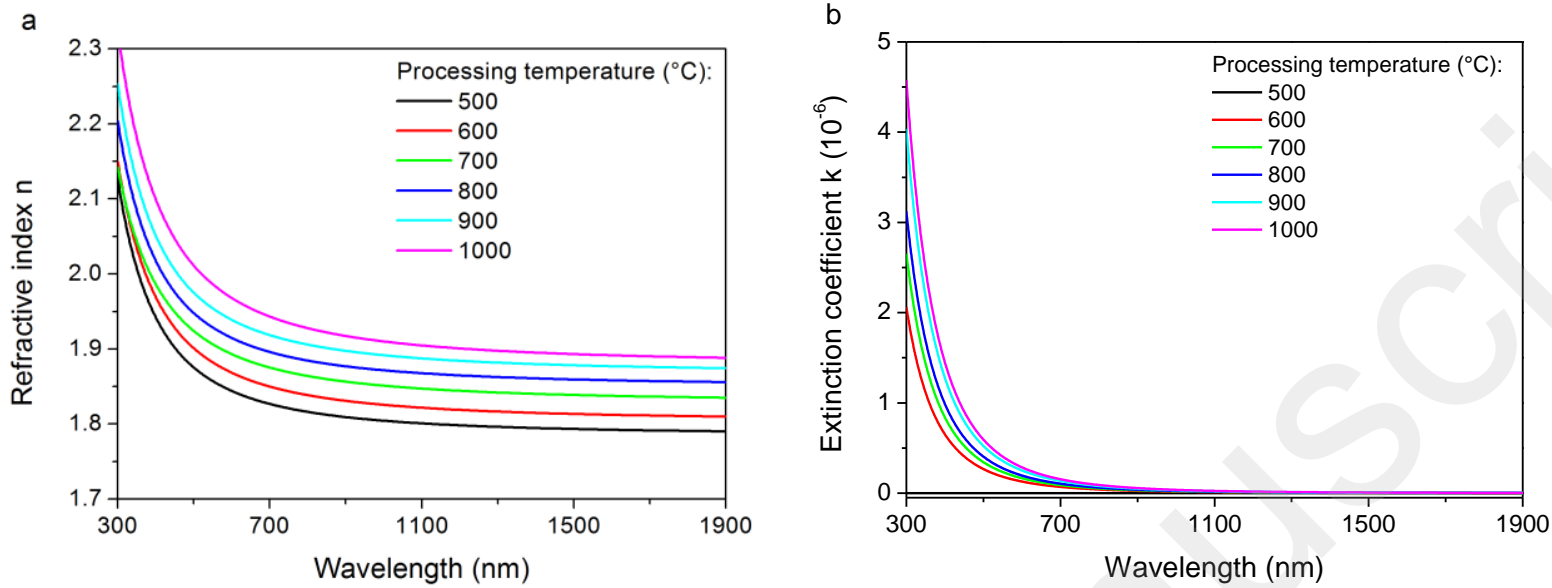

Figure 3. Spectral dependence of (a) the real part of the refractive index $n$ and (b) the extinction coefficient $k$ of $\mathrm{Zn}_{2} \mathrm{TiO}_{4}$ films for various processing temperatures. 


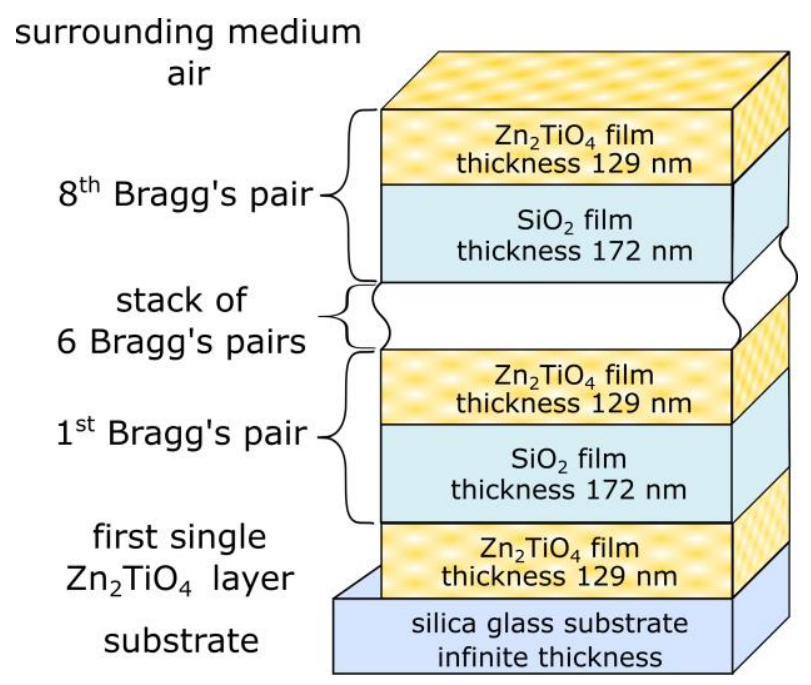

Figure 4. The scheme of the designed DBR structure. 

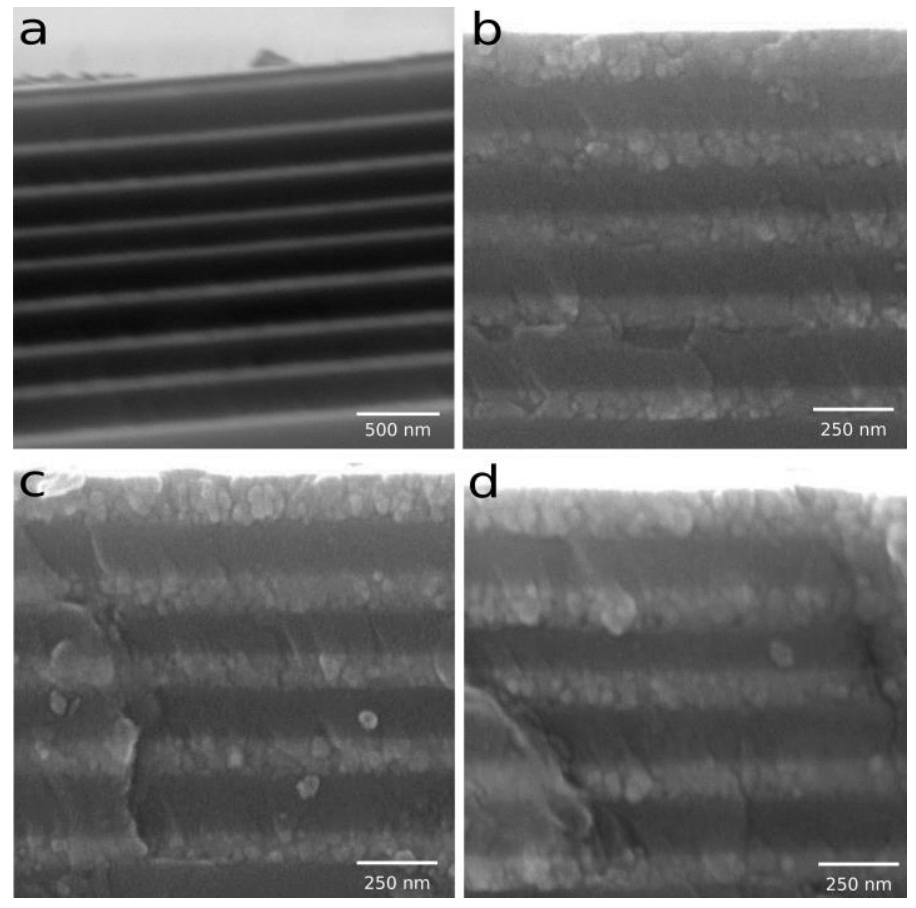

Figure 5. Secondary electron SEM images of cross-sections of the prepared DBR's structure. (a) Overall cross-sectional view on DBR. (b, c, d) Random zooms on the cross-section. 

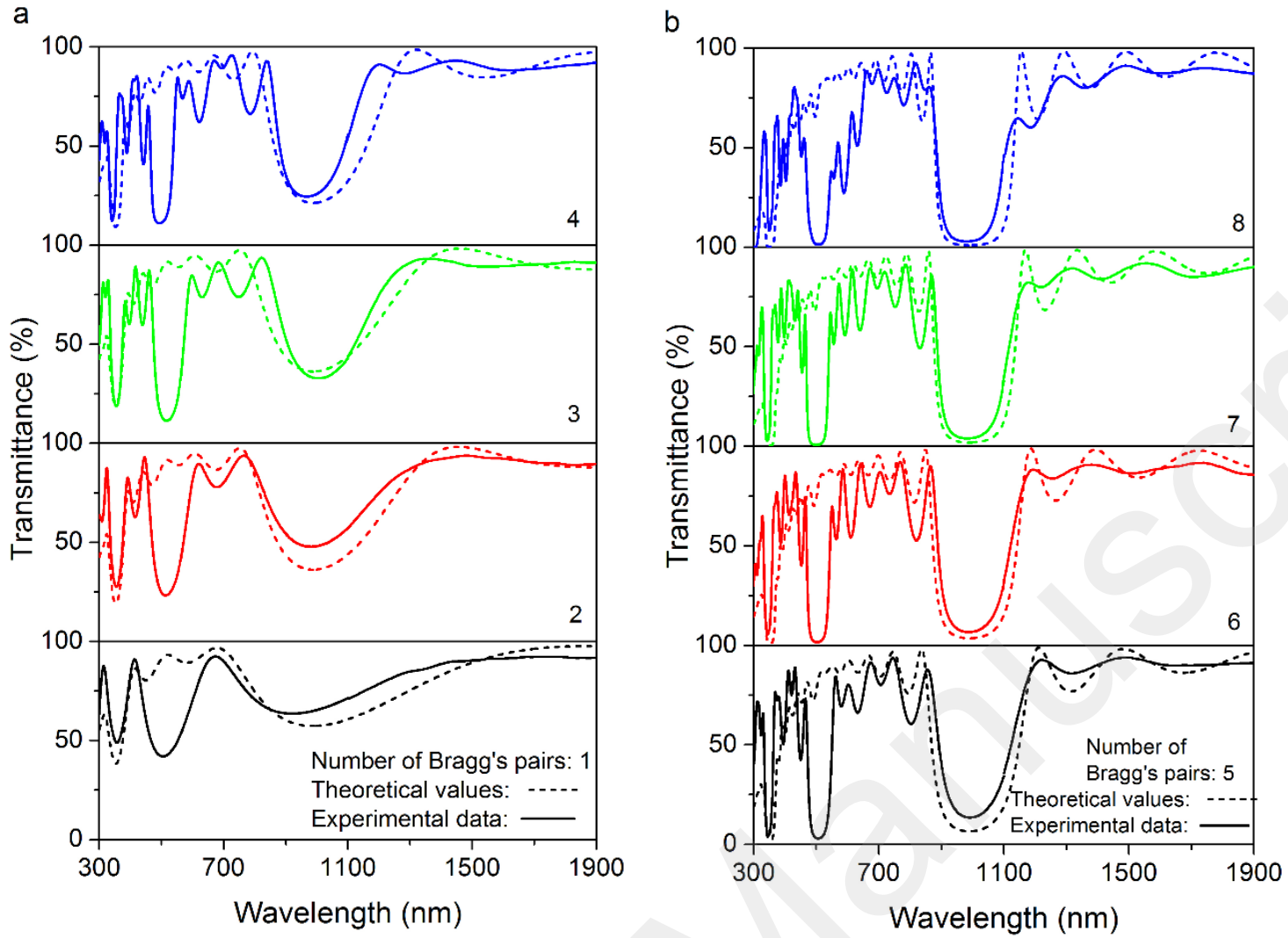

Figure 6. Evolution of the transmittance spectra od DBR as the number of Bragg's pairs. Simulated theoretical values are depicted in dashed lines, experimental data in solid lines. 


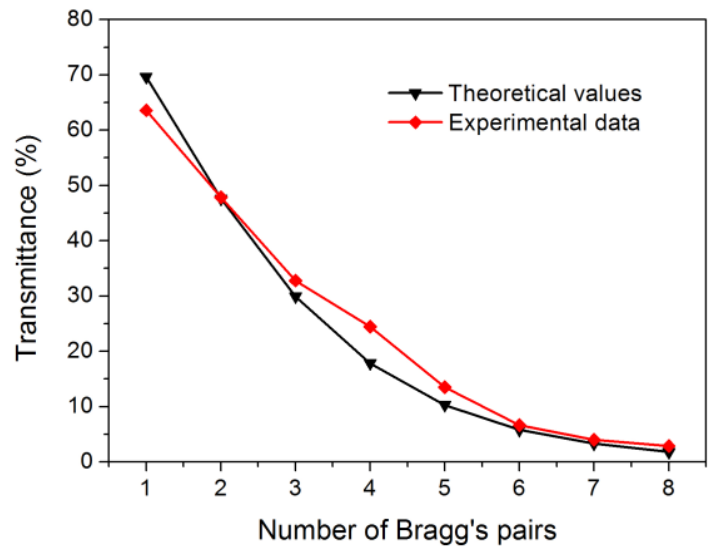

Figure 7. Comparison of theoretical and experimental values of transmittance in the central Bragg's peak position as a number of Bragg's pairs.

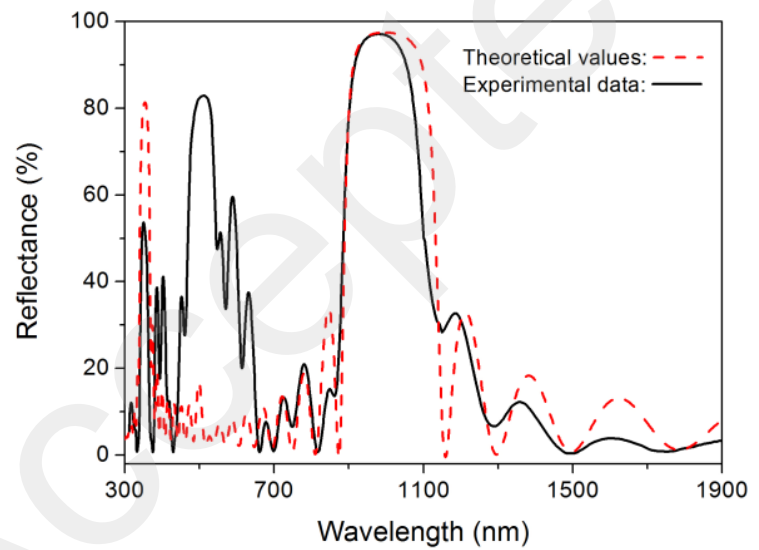

Figure 8. Spectral reflectance of the final DBR composed of 8 Bragg's pairs. 


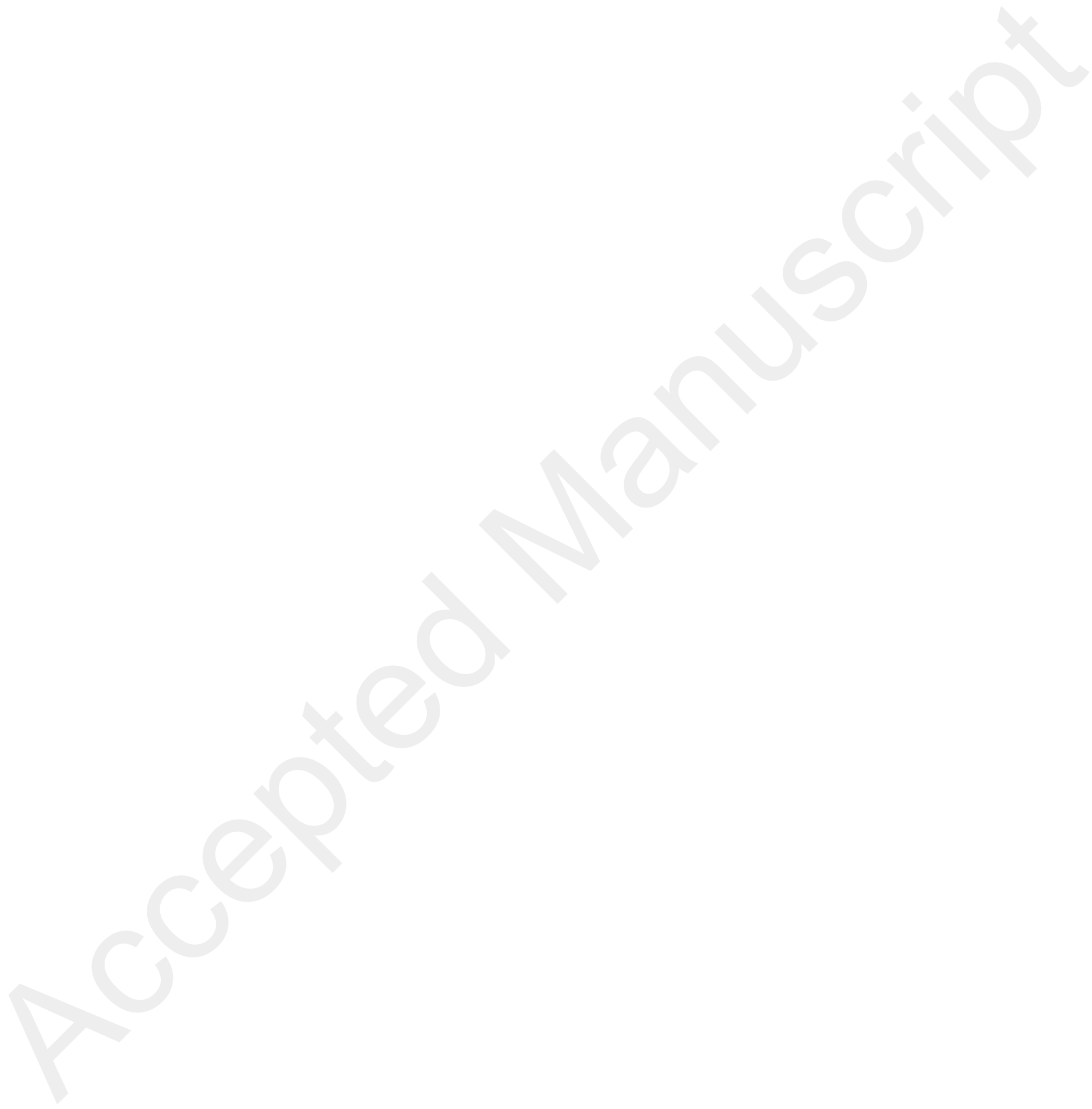

